\title{
Stigmatizing Attitudes of the Community Towards People Living with HIV/AIDS
}

\author{
MARETHA J. VISSER, ${ }^{1 *}$ JENNIFER D. MAKIN ${ }^{2}$ and KOPO LEHOBYE ${ }^{1}$ \\ ${ }^{1}$ Department of Psychology, University of Pretoria, Brooklyn, Pretoria, South Africa \\ ${ }^{2}$ Department of Obstetrics and Gynaecology, University of Pretoria/Medical Research Unit for Maternal \\ and Infant Health Care Strategie, South Africa
}

\begin{abstract}
This research involved an exploratory study in which a questionnaire was used to investigate the personal stigma and perceived community stigma regarding HIV/AIDS in a South African community. Student fieldworkers interviewed a convenient sample of 901 respondents from different races, gender and age groups, and found that respondents tended towards stigmatizing persons with HIV/ AIDS. Yet, this degree of stigmatization was significantly less severe than the degree of stigmatization that respondents attributed to the community at large. Altogether $17 \%$ of the respondents had high stigmatizing attitudes, while $42 \%$ perceived the stigmatization by others in the community to be high. Race group, personal knowledge of someone with HIV, area of residence, gender and age group impacted on the respondents' personal tendency to stigmatize those with HIV/AIDS. The article discusses the difference between the level of personal stigma attached by the respondents and that perceived by them to be attached by the community. Attention is also paid to the possible implications of stigmatizing behaviour patterns and interventions on a community level. Copyright \# 2006 John Wiley \& Sons, Ltd.
\end{abstract}

Key words: HIV/AIDS stigma; personal stigma; perceived community stigma; quantitative stigma measure

\section{INTRODUCTION}

HIV/AIDS is one of the most complicated and bewildering social challenges faced by contemporary society. Eversince HIV/AIDS became a known disease in the 1980s it has been associated with fear, stigmatization and discrimination. Jonathan Mann spoke about a third epidemic of discrimination that would follow the HIV and then the AIDS epidemic. He asserted that this third epidemic was as central to the global AIDS challenge as the disease itself (Parker, Aggleton, Attawell, Pulerwits, \& Brown, 2002). Despite numerous conferences and international efforts to change the negative attitudes and discrimination

\footnotetext{
* Correspondence to: Maretha Visser, Department of Psychology, University of Pretoria, Brooklyn, Pretoria 0002, South Africa. E-mail: maretha.visser@up.ac.za

Contract/grant sponsor: National Institute of Health.
} 
associated with HIV/AIDS, the disease continues to carry a significant stigma that impacts on many areas of community life (Aggleton, 2000; Gostin \& Weber, 1998; Herek, 1999; Herek, Capitanio, \& Widaman, 2002).

The stigma related to HIV is a major barrier to curbing the HIV/AIDS pandemic worldwide because it drives the epidemic underground. Stigma is considered as one of the main reasons why people do not wish to know their HIV status, do not protect themselves and others from the virus, do not go for treatment and do not care and support people living with HIV - it negatively affects all aspects of HIV prevention, diagnosis, treatment and care (Aggleton, 2000; Bond, Chase, \& Aggleton, 2002; Brown, Trujillo, \& Macintyre, 2001; Malcolm et al., 1998).

Reluctance to go for HIV testing and fear of disclosing HIV status is a common characteristic of the South African community (Gebrekristos, Abdool Karim, \& Lurie, 2003; Skinner, 2002). This may result from continuous media reporting on violence and discrimination against people with HIV/AIDS (Keeten, 1999; Maman et al., 2001) and the government's ambivalent response to the epidemic. Despite many reports on stigma and discrimination, many people do experience acceptance and support from family members and friends (Department of Health, 2000a). To understand the reaction of the community towards HIV, a systematic analysis of the nature and practice of stigma is required. South African research regarding the community reaction towards HIV focuses on narratives and qualitative analyses of the experiences of people living with HIV/AIDS (Department of Health, 2000a; Gebrekristos et al., 2003; Skinner, 2002; Strebel, 1993). There is insufficient documented research that investigates the nature and level of stigma the community attaches to HIV (Skinner, 2002).

The aim of this research was to develop an instrument to explore the level of HIV/AIDS stigma and the perceived stigma in the community expressed by various sub-groups. It was felt that an understanding of HIV-related stigma could contribute to the development of effective community interventions.

In order to obtain a better understanding of stigmatizing attitudes, the concept of stigma, stigmatizing in the context of HIV/AIDS, as well as the situation in South Africa where the HIV/AIDS epidemic has a huge impact on the community, will be examined in the paragraphs that follow.

\section{HIV-RELATED STIGMA}

Stigma is a multi-dimensional concept of which the essence focuses on deviance or departure from an accepted standard or convention. The term stigma originates from the Greek language and refers to a tattoo mark branded on the skin of an individual as a result of some incriminating action, identifying the person as someone to be avoided (Crawford, 1996). In the social sciences stigma can be described as a social construction of deviation from an ideal or expectation, contributing to a powerful discrediting social label that radically changes the way individuals see themselves and are viewed as persons (Goffman, 1963). The attribute is not inherently deviant, but the deviance derives from culturally imbedded meanings in the context of a particular historic period and cultural context. AIDS-related stigma is defined as 'prejudice, discounting, discrediting and discrimination directed at people perceived to have AIDS or HIV and individuals, groups and communities with whom they are associated' (Herek, 1999, p. 1102). Stigmatization related to HIV/AIDS is abundant, ranging from subtle actions and discriminatory practices to the 
most extreme degradation, rejection, abandonment and physical violence (Bond et al., 2002; National Association of People with AIDS, 1992).

Stigmatization is not only the expression of individual attitudes, but also involves social processes based on social, economic and political power. Power is required to be able to introduce stigma and to remove power from the stigmatized person (Link \& Phelan, 2002). Stigmatization and discrimination as social processes are used to create and maintain social control and to produce and reproduce social inequality. Stigma contributes to the creation of social hierarchy in a community and then in turn legitimises and perpetuates social inequality (Parker et al., 2002).

Crawford (1996) found in a meta-analysis of 21 studies that the degree of stigma associated with HIV/AIDS is more than that associated with any other comparable terminal illness. Malcolm et al. (1998) identify the metaphors associated with HIV/AIDS as following: death; punishment for immoral behaviour; a crime described in terms of innocence and guilt; a war that has to be fought against; horror and fear; shameful and a social disgrace. These metaphors that underlie behaviour towards people with HIV/AIDS can be seen as a convergence of many types and dimensions of stigma linked to the infection itself and to behaviours believed to contribute to infection. Alonzo and Reynolds (1995) and De Bruyn (1999) identified four factors that contribute to HIV/AIDS-related stigma:

- HIV/AIDS is a life-threatening disease, perceived as contagious and threatening to the community. The disease is not well understood, which results in fear of contracting HIV.

- People living with HIV are often seen as being responsible for having contracted the disease, which increases the attribution of guilt.

- HIV/AIDS is related to behaviour sanctioned by religious and moral beliefs, which results in the perception that HIV/AIDS is the result of deviant behaviour and consequently deserves punishment.

- HIV/AIDS is associated with pre-existing social prejudices such as sexual promiscuity, homosexuality and drug use - behaviour that is already considered 'less worthy' in many societies. HIV thus adds to existing societal judgement.

HIV-related stigma is therefore born from fear, ignorance, social judgement and control. The marginalisation and exclusion of individuals from interaction has possibly originated as a defence mechanism to protect the community from infection. Individual reactions, media reporting, reactions of community leaders and governments have all contributed to the development of a collective community reaction against HIV/AIDS. Different kinds of stigma can be distinguished at different levels:

- At an individual level, experienced stigma involves the perceptions that individuals with the stigmatised attribute have about the attitudes and reactions they expect and experience from others. Individuals often internalise the norms of the wider community that disqualify them from equal participation - they therefore discredit themselves (Goffman, 1963).

- Enacted stigma refers to the stigmatization and discrimination actually experienced by the infected person on an interpersonal level.

- Each person has an attitude towards people with HIV - a personal attitude or stigma that often impacts on his or her behaviour. One way of assessing the level of stigma in the community is by assessing personal perceptions of HIV/AIDS in a group of people (Green, 1995). 
- The interaction between community members, media reports and reactions of leaders contribute to the meanings that people attach to situations and the development of shared social constructions that represent the way people agree to think about and react towards a phenomenon (Gergen, 1994). According to various theories (Ajzen, 1991; Ajzen \& Fishbein, 1980; Gergen, 1994) the perception of community beliefs, shared social constructions and discourses have an impact on the behaviour of individuals. This can be conceptualised as the community stigma. The perceived community stigma can be assessed by asking community members how they think most people in their community feel about and react towards HIV/AIDS (Green, 1995).

Personal and perceived community stigma can be distinguished in terms of focus. Personal stigma focuses on the individual's attitude based on personal experiences, while the perceived community stigma focuses on the observation of the reaction of other people in the community. There may be an overlap between the concepts, because perceptions regarding the attitudes of others may be coloured by one's own attitudes. Personal attitudes are also informed by community constructions (Gergen, 1994).

Research on stigma often explores the stigma experienced by people who live with HIV. More research is however needed on the perceptions of, and stigmatizing attitudes in, the community.

\section{HIV/AIDS IN THE SOUTH AFRICAN CONTEXT}

Although HIV/AIDS is a highly stigmatized disease worldwide (Malcolm et al., 1998), the exact form of stigma is probably unique in each community because each community attaches its own meanings and explanations to situations. Stigma therefore needs to be considered in a specific social and cultural context.

HIV infection has reached epidemic proportions in South Africa and has serious consequences for individuals as well as for the country's health resources and economy. According to a nationally representative survey of HIV prevalence (Shisana \& Simbayi, 2002), $11.4 \%$ of the country's population of two years and more were living with HIV/ AIDS in $2002-12.8 \%$ of the women and $9.5 \%$ of the men. The prevalence rate amongst Africans was $12.9 \%$, the prevalence amongst whites and coloureds was similar $(6.2 \%$ and $6.1 \%$ respectively) and amongst Indians it was $1.6 \%$. The highest prevalence was in the age group of 25-29 (28\%), followed by the age group of 30-34 (25\%). People living in urban informal settlements were more vulnerable to HIV/AIDS (28.4\%) than those living in urban formal settlements $(15.8 \%)$, on farms $(11.3 \%)$ and in rural areas $(12.4 \%)$. According to the latest figures, 5.3 million people in South Africa are living with HIV (Department of Health, 2003).

In Western countries the fear and hostility towards people living with HIV/AIDS is often associated with negative attitudes towards homosexuality and drug use (Herek \& Glunt, 1991; St Lawrence, Husfeldt, Kelly, Hood, \& Smith, 1990). In Africa HIV/AIDS is predominantly transmitted through heterosexual contact and from mother to child (Department of Health, 2003). Research in South Africa shows that HIV/AIDS flourishes in areas where high levels of unemployment, poverty and overcrowding, prostitution, crime, high school dropout rates and social and political instability occur (Abdool Karim, 1998; Evian, 1992; Lindegger \& Wood, 1995; Schoub, 1992). Because of traditional gender roles women are especially vulnerable, as they are economically and socially 
disadvantaged and often lack equal access to societal institutions (Abdool Karim, 1998; De Bruyn, 1992; Strebel, 1993; Warwick et al., 1998). Women are often erroneously perceived as the main transmitters of HIV/AIDS, while men are 'excused' for high-risk sexual behaviour. Having multiple sexual partners is culturally more acceptable for males than for females (Warwick et al., 1998).

The stigma related to HIV in Africa mainly centers around moral issues such as being promiscuous, 'dirty', irresponsible (Bond et al., 2002) and 'bewitched' (Ashforth, 2002; Bond et al., 2002). Fear, ignorance and misinformation are also dominant factors in people's reaction towards HIV/AIDS (Bond et al., 2002).

\section{Stigmatizing attitudes in the South African context}

Although HIV/AIDS in South Africa started later than in other African countries due to relative political and economic isolation during the 1980s (Grimond, 2001), there was a lack of early response from the South African government to the epidemic. This contributed to community apathy and denial, and to the development of many misconceptions. It was only in 1992 that the government of that time acknowledged the impending threat of HIV and commissioned a comprehensive AIDS research programme (Department of National Health and Population Development, 1993). At that time the country was involved in a political turmoil due to a long history of apartheid and attempts to end the regime, with the result that other socio-political issues were far more important than HIV/AIDS. Relationships were characterised by mistrust, suspicion and aggression and all communication was seen as political, and part of an ongoing 'racial war'. Misconceptions regarding HIV emerged, such as that HIV was a war strategy invented by the apartheid government or a disease to stop black population growth.

After the 1994 democratic election, radical changes took place at almost all levels of the society, again keeping people involved in many other issues and hampering a serious dedication to combating the spread of HIV/AIDS. According to Sherriffs (1997, p. 11) '[m]uch of the response to AIDS has been too much talk and too little action: plans are made, committees formed and strategies drafted. Few keep to their time frames and many end up as little more than folders on a bookshelf. We knew about AIDS so long but we didn't do enough and now it is too late. We have lost half a generation of time to do something significant'. It was only in 2000 that a comprehensive strategic plan was drawn up to combat HIV/AIDS at various levels in the community (Department of Health, 2000b).

In the health sector the management of HIV/AIDS is still characterized by a general ambivalence. Due to the many conflicting attitudes and emotions it has taken years of campaigning to convince the government to provide antiretroviral treatment to persons who are HIV positive (Forman, 2003; Hassan, 2003). The role of government in decisions about HIV/AIDS is unmistakably important (Sakufiwa, 2003) and in South Africa's case has unfortunately resulted in denial of the magnitude of the epidemic, the inhibition of prevention strategies and HIV-testing, and discrimination against people living with HIV/AIDS (Malcolm et al., 1998).

On a legal level there has been some progress with regard to the development of nondiscriminatory laws and policies that protect the human rights of people living with HIV. Recent legislation aims to ensure not only their right to employment, education, privacy and confidentiality, but also their right to remain a part of the society and receive information, health services and support (Mwondela \& Sakufiwa, 2003; Richter, 2003). Legislation and policy formulation have been a positive step towards addressing discrimination. 
However, legislation needs to be enforced before it will have any real impact on community behaviour.

Media reports on violence and discrimination may well have contributed to the development of community stigma. Examples are the following:

- Reports on the death of Gugu Dlamini who was killed because she openly stated that she was HIV positive (Baleta, 1999; Mc Neil, 1998)

- Reports on the experiences of Nkosi Johnson and other children who were barred from attending school because they had disclosed their status (Streek, 2001)

- Reports about discrimination in the work place (Ngqlyaza, 2000a; Viol, 2000), in the military service (Ngqlyaza, 2000b) and in the healthcare setting (Krautkamer, 2000)

- Reports of severe rejection and isolation in families (Altenroxel, 2000).

All these stories had stigma and discrimination as common themes, and may have impacted on the development of community stigma.

Legal action to protect human rights cannot protect people from the different forms of discrimination, which range from subtle prejudice to violence. The mere fear of discrimination can create an environment of distrust and eventually limit the extent to which much needed services are accessed. Daniel and Parker (in Aggleton, 2000) describe stigmatization as a kind of 'social death' in which individuals no longer feel part of society and cannot access the services and support they need. People are sometimes more fearful of the social consequences of AIDS than of the disease itself (Bond et al., 2002; Lie \& Biswalo, 1994).

It was against this background that the community stigma regarding HIV/AIDS in South Africa developed. The perception of stigmatization appears to be anchored in what people understand to be the common beliefs in their community. This research explores the HIV/AIDS-related stigma that developed in this way.

\section{METHODOLOGY}

The stigma related to HIV/AIDS in a South African community was investigated in an exploratory study.

\section{The respondents}

A convenient sample of 901 respondents from the community around the Tshwane metropolitan area participated in the research. Third-year psychology students from the University of Pretoria recruited respondents in their neighbourhoods from different gender, race and age groups to complete the questionnaire. This was an assignment for a Community Psychology course, where students were trained in interviewing skills, data collection and research ethics. The students worked in groups where they could assist and criticize the research approach of their peers. When they handed in their results, the lecturer had a reflective discussion with the students during which the quality of the data was controlled. Participation of the respondents was based on informed consent and was completely voluntary.

\section{Measuring instrument}

Items from existing questionnaires (Green, 1995; Herek \& Capitanio, 1993; Westbrook \& Bauman, 1996) were selected and adapted to constitute a stigma scale. Three of the subscales suggested by Herek and Capitanio (1993) were used: the attribution of blame 
and responsibility, interaction with HIV positive people and human rights issues. The sub-scale assessing affection was not used but was replaced by questions that assessed the cognitive image people have of HIV, as suggested by Green (1995). The questions were answered on a 4-point Lickert scale that ranged from 1 (strongly agree) to 4 (strongly disagree). Two scales were constructed to assess different aspects of stigma:

- Respondents had to answer questions regarding their own perception of and reaction towards people with HIV/AIDS - thus reflecting their personal stigma.

- The same questions were asked about the respondent's perception of most people in the community's reaction towards HIV/AIDS - thus reflecting the perceived community stigma.

As stated before, the questionnaire was administered to 901 respondents. In a factor analysis, the following three underlying factors were identified:

Factor 1: Human rights and HIV (10 items), $\mathbf{a}=0.84$ Factor 2:

Personal interaction (6 items), $\boldsymbol{a}=0.75$ Factor 3 : Blame and

judgement ( 5 items), $\mathbf{a}=0.71$

The Cronbach alpha reliability coefficient for the personal stigma scale as a whole was 0.896 .

The perceived community stigma scale had a reliability coefficient of 0.866 and the reliability coefficients for factors 1,2 and 3 were $0.74,0.78$, and 0.74 , respectively. The internal consistency of both scales was therefore regarded as high (Kerlinger \& Lee, 2000).

In addition, the questionnaire contained a section on biographical information and an open question that explored the respondents' perception of HIV: 'What is the first thought that comes to your mind if I say 'HIV/AIDS'?'

\section{Data analysis}

Two researchers coded the qualitative responses according to the themes by employing a process of content analysis (Miles \& Huberman, 1994).

After the item and factor analysis of the two scales, the total scale scores of each scale were computed -88 being the maximum score and 22 the minimum. A high score indicated a high stigma level. A paired t-test was used to assess the statistical significance of the difference between the two scale scores. In this analysis, 130 questionnaires could not be used due to certain missing values. The relationship between age, gender, race group, living area, contact with someone with HIV/AIDS on the one hand, and reported stigma levels on the other hand, was investigated by means of a stepwise regression analysis and $t$-tests for independent variables (Kerlinger \& Lee, 2000).

\section{RESULTS}

\section{Biographical data of respondents}

The sample consisted of the following respondents:

- $380(42 \%)$ of the respondents in the sample were male, while $517(58 \%)$ were female. (A total of 4 respondents did not indicate their gender).

- 578 (64\%) of the respondents were under 25 years of age, while 317 (35\%) were older than 25 years of age (6 respondents did not indicate their age). 
- The majority of the respondents $525(58 \%)$ were white, 265 (29\%) were black, while $7 \%$ and $5 \%$ were coloured and Indian, respectively.

- The majority of the sample 744 (83\%) came from urban areas and 134 (15\%) were from rural areas. Two per cent of the respondents did not complete the question.

It is clear from the above findings that the sample cannot be claimed to be a representative sample of the population, since both the younger age group and whites are over-represented. This fact should be kept in mind in the interpretation of the data.

\section{Perception of HIV/AIDS}

The majority of the respondents' first association with HIV/AIDS was that it is a deadly disease (50.8\%), transmitted sexually (9\%) and associated with moral issues (8.4\%). They also perceived it to be accompanied by feelings of hopelessness and pity (8.2\%), pain and suffering (5\%) and fear (4.9\%). Interestingly, only $1.4 \%$ and $0.7 \%$ of the respondents associated in HIV/AIDS with drug use and homosexuality, respectively. The main discourses that were found to underlie people's perceptions of HIV/AIDS are therefore related to death, sex, moral issues, pity and fear.

\section{Personal and perceived community stigma}

In order to understand the personal and perceived community stigma, the responses to some of the items are given in Table 1. The categories 'strongly agree' and 'agree' were combined into a positive response.

Table 1. Personal and perceived community stigma responses

$$
\begin{array}{rc}
\text { Personal } & \text { Perceived } \\
\text { stigma } & \text { community stigma }
\end{array}
$$

Human rights

The human rights of HIV positive people should be protected just like $88 \%$ everybody else's

HIV positive people deserve as much respect as anyone else $\quad 86 \%$

The needs and rights of people with HIV should be given

$40 \%$

$66 \%$

top priority

The names of people with AIDS should be made public to protect $\quad 10 \%$ the public health

HIV positive people should not receive free medication - it will cost $\mathrm{t} 3 \mathrm{~h} 6 \mathrm{e} \%$ country a fortune

Employers will not hire someone with HIV to work for them $\quad 55 \%$

Personal interaction

Feel uncomfortable around someone with HIV

Afraid to be around a person with HIV

People with HIV should not take care of other people's children

$\begin{array}{ll}\text { Will not date a person if it was known that the person has HIV } & 72 \% \\ \text { Will not stay friends when a close friend has HIV } & 11 \%\end{array}$

Will be upset if someone with HIV moved in next door

$13 \%$

Judgement and blame

HIV is a punishment for bad behaviour

$22 \%$

People who got HIV through sex or drugs got what they deserve

People with HIV have only themselves to blame

$45 \%$ 
Personal stigma. Majority of respondents agreed that the human rights of people with HIV should be protected ( $88 \%$ ) and that they deserve respect $(86 \%)$, but not at the expense of other people $(40 \%)$. Isolation as a preventive measure was not considered a viable option $(10 \%)$. The controversy around the provision of antiretroviral medication is visible in that $36 \%$ of the respondents did not agree to the provision of free medication because of the cost implications to broader society.

On an interpersonal level the respondents reported feeling uncomfortable around people with HIV (44\%) and afraid (35\%), while $72 \%$ would not date someone with HIV-the closer the contact the stronger was their negative response. A strong moral judgement could be detected, as $61 \%$ of the respondents did not regard people with HIV as of good moral character. A total of $22 \%$ considered HIV as a punishment for bad behaviour, and $26 \%$ blamed individuals for contracting HIV/AIDS - especially if they got it through sex and drug use (45\%).

Perceived community stigma. The respondents perceived the community's reaction to HIV/AIDS to be far more negative than their own (Table 1). The respondents thought that most people regarded HIVas punishment for bad behaviour (55\%) and judged people living with HIVon moral grounds $(80 \%)$. It was their perception that the community would feel that people with HIV should be ashamed (57\%) and blamed (67\%), especially if they contracted HIV through sex or drug use $(72 \%)$. On an interpersonal level, they believed that most people would feel uncomfortable around people with HIV $(80 \%)$; afraid $(80 \%)$ and not willing to date people with HIV (89\%). The respondents' perception was that the community would favour coercive isolation (43\%); that employers would not hire people with HIV (75\%); that people would not allow someone with HIV to take care of their children $(82 \%)$; and that free medication should not be provided $(57 \%)$.

The level of HIV/AIDS stigma in the community

The frequency distributions of the scale scores for personal stigma and for perceived community stigma are graphically presented in Figures 1 and 2. Because these HIV/AIDS stigma questionnaires have not been standardized, a categorization based on informed judgement was made: The lowest scores, between 22 and 44, were considered as low stigma and the highest scores, between 66 and 88 , as high stigma.

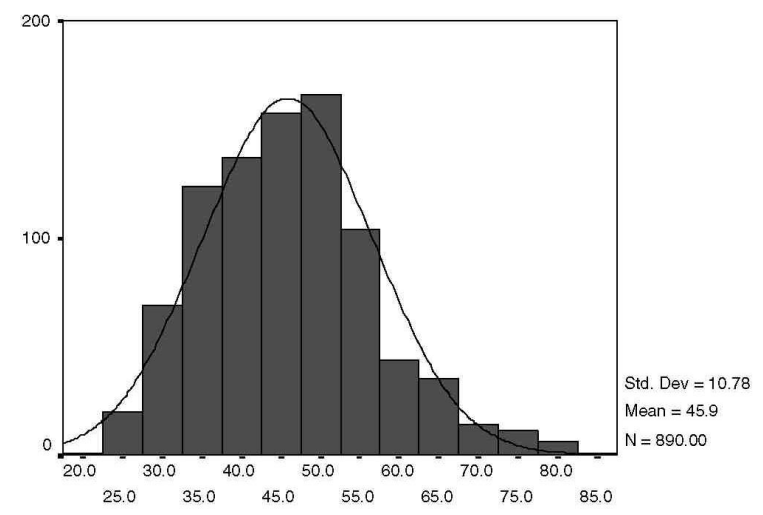

Figure 1. Personal stigma: frequency distribution of scale scores. 


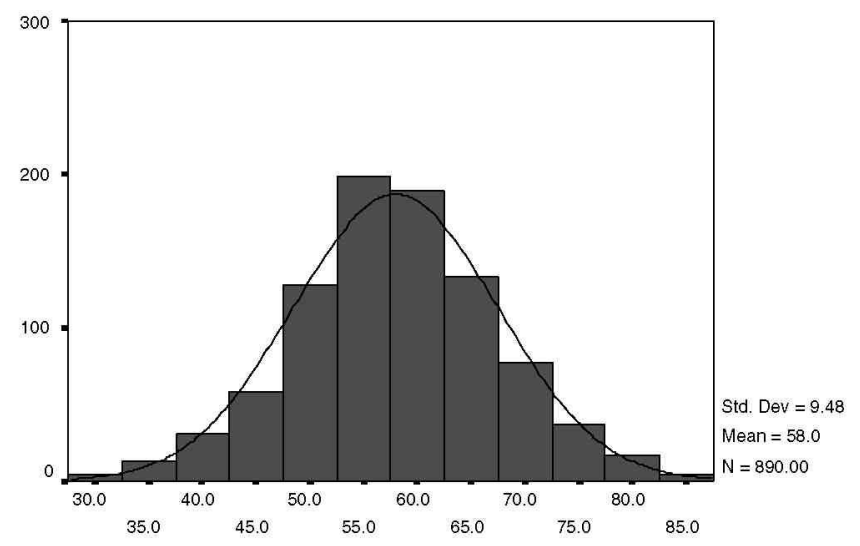

Figure 2. Perceived community stigma: Frequency distribution of scale scores.

The average personal stigma presented in Figure 1 was 45.9, which can be considered an average level of stigma. Seventeen per cent (17\%) of the respondents had a scale score of higher than 66 , which can be considered as a high stigmatizing attitude, while $22 \%$ had low stigmatizing attitudes (below 44).

The mean scale score on the perceived community stigma scale was 58 - also an average score. The scale scores of $42 \%$ of the respondents indicated that they perceived high stigmatizing attitudes in the community.

\section{The difference between personal stigma and perceived community stigma}

The paired t-test was used to assess the significance of differences between the personal and perceived community stigma scores (Table 2). (Because of missing values the data of 130 respondents was excluded in the analysis).

There was a significant difference $(p<0.0001)$ between the personal stigma scores and the perceived community stigma scores. The perceived community stigma was significantly higher than the stigma that individuals attached to HIV/AIDS.

\section{Stigma in different sub-groups}

Table 2. T-tests comparing personal and perceived community stigma

\begin{tabular}{|c|c|c|c|c|c|c|}
\hline \multicolumn{2}{|c|}{ Personal perception } & \multicolumn{2}{|c|}{ Perceived community perception } & \multirow[t]{2}{*}{$n$} & \multirow[t]{2}{*}{$t$ value } & \multirow[t]{2}{*}{$p$ value } \\
\hline Mean & $S D$ & Mean & $S D$ & & & \\
\hline 46.2 & 10.69 & 57.5 & 8.66 & 771 & -11.30 & 0.0000 \\
\hline
\end{tabular}

The relationships between biographical data of the respondents and the personal and perceived community stigma were assessed by means of t-tests for independent samples, an analysis of variance (one way ANOVA) (Table 3), as well as a regression analysis.

From Table 3 it can be seen that female respondents $(p<0.001)$, people younger than 25 years of age $(\mathrm{p}<0.001)$, people staying in urban areas $(\mathrm{p}<0.01)$ and people who knew someone with HIV/AIDS $(p<0.001)$ display significantly more positive attitudes 
Table 3. Personal stigma among subgroups of respondents

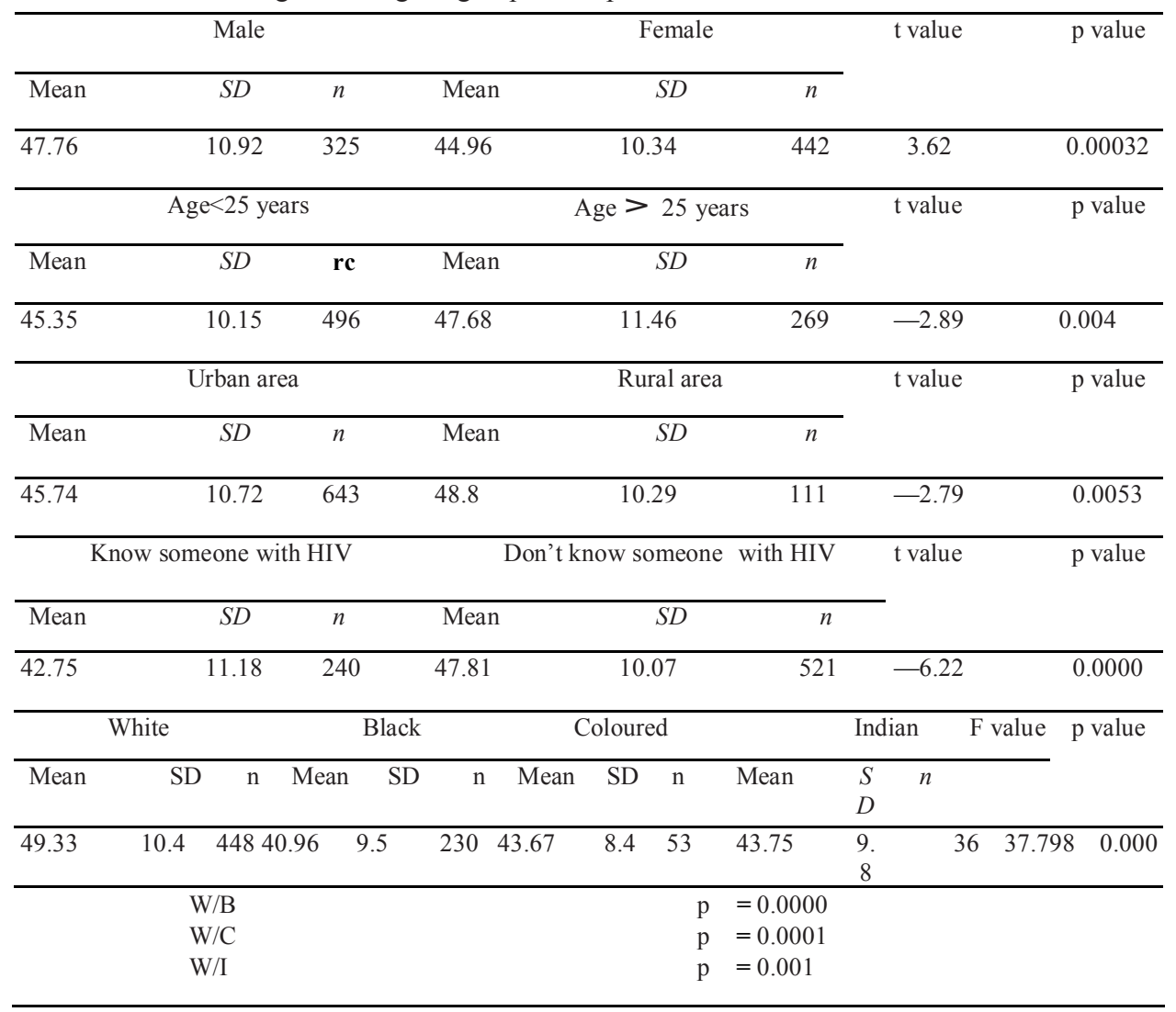

towards people with HIV. It was also found that the white respondents had significantly stronger stigmatizing attitudes towards people with HIV/AIDS $(p<0.001)$ than the other main race groups in South Africa. Black respondents were the least stigmatizing. A factor that may have had an impact on these results is the fact that significantly more black respondents $(60 \%)$ knew someone with HIV, compared to only $16 \%$ of the white respondents.

In a stepwise regression analysis personal stigma scores were predicted best by race, knowing someone with HIV, living area, gender and age group - in same sequence. These variables explained $13 \%$ of the variance in the personal stigma scores.

The relationship between biographical data and perceived community stigma was investigated in the same way. It was found that respondents younger than 25 years of age perceived the community stigma to be more negative than the respondents more than 25 years $(p<0.01)$. All the other groups had similar views about the level of stigma that the community attached to HIV/AIDS.

\section{DISCUSSION}

In the third decade of the HIV/AIDS epidemic, $17 \%$ of a sample of people in South Africa indicated that they still had highly stigmatizing attitudes towards people living with 
HIV/AIDS and $42 \%$ of them perceived the community to attach a high stigma to HIV/ AIDS. The most prominent metaphors underlying the respondents' attitudes were that of HIV/AIDS as a deadly disease, as horror and human suffering and as punishment for bad behaviour. These responses agree with the images of HIV/AIDS in Africa gained from various studies (Abdool Karim, 1998; Bond et al., 2002), and with the metaphors identified by Malcolm et al. (1998). These metaphors could well influence the manner in which people react towards people with HIV (Baron \& Byrne, 2002).

More than a third of the respondents were afraid and uncomfortable interacting with HIV positive people, especially where children and intimate behaviour such as dating were involved. Moral judgement was strong, especially if HIV/AIDS had been contracted through sex and drug use. The majority of the respondents agreed that the human rights of HIV positive people should be protected, but not at the expense of other people's rights and needs. Similar to the results obtained by Herek et al. (2002), it was found that a small percentage of the respondents $(10 \%)$ agreed to radical discrimination such as coercive isolation of people with HIV/AIDS.

Race, knowing someone with HIV, living area, gender and age were the most important variables in explaining the level of personal stigma. White respondents were more stigmatizing than other groups, while black respondents, who were exposed to the HIV epidemic to a much greater extent, were least stigmatizing. People who knew someone with HIV were less stigmatizsing than people who did not know someone, which corresponds with the results of Herek and Capitanio (1997). Exposure to HIV may explain some of the differences between the sub-groups, since HIV is more prevalent in the black community, urban areas, amongst the younger age group and amongst women (Shisana \& Simbayi, 2002). Black respondents, young people and respondents in urban areas also indicated that they knew more people with HIV than did their counterparts. Female repondents who were also caregivers in families were more understanding and sympathetic - in keeping with their gender role (Abdool Karim, 1998; Baron \& Byrne, 2002). Research by Crawford (1996), Green (1995), as well as Herek and Capitanio (1993) showed the same differences in personal stigma between sub-groups.

The level of stigma that individual respondents attached to HIV was significantly lower than the level of stigma that they perceived others in the community to attach to HIV/ AIDS. This indicates that people perceive a collective stigma in the community that is negative, blaming and restrictive towards interaction with people with HIV. The perception of highly stigmatizing attitudes in the community was shared by all sub-groups in the study.

It can only be speculated why the personal stigma differs significantly from the perceived community stigma. According to the social comparison theory described in Green (1995), a person compares himself/herself to others and there is a tendency to see the self as more positive and better than the average. There might have been an over-estimation of the negative stigma of others in relation with the self. The sympathy a person might feel for a person with a terminal illness can also be incorporated in the assessment of the personal stigma.

Community stigma, on the other hand, cannot be seen as the accumulation of individual attitudes. The community stigma as a social construction (Parker et al., 2002) develops over many years, as a result of various influences such as media reports, government responses and policies that impact on community processes. It should be kept in mind that one public incident of stigmatization has a huge impact on the community as a whole, and contributes to perceived community stigma. Since the start of the epidemic in South 
Africa, media reports on HIV/AIDS have been negative, and the government's reaction ambivalent, both of which contribute to high stigmatizing attitudes.

The most important question is - which measure of stigma gives a true indication of the level of stigmatizing attitudes and discrimination in the community? The personal stigma scale was used to assess the attitude and behavioural intentions of respondents. Although attitudes often find expression in an individual's ongoing behaviour patterns, they do not necessarily predict specific behaviours in particular situations (Eagle \& Chaiken, 1993). An individual's publicly reported attitude may also not necessarily be synonymous with his/her private beliefs and behaviour. Green (1995) argues that it might be easier to be liberal in a hypothetical situation than in reality, where one is confronted with the various levels of social stigma. Since most of the respondents in this study $(68 \%)$ did not have any personal contact with people living with HIV, theirs was actually an attitude based on a hypothetical situation. Behaviour is also not determined by personal attitudes only. According to Ajzen and Fishbein (1980) and Ajzen (1991), behaviour may be influenced by a combination of personal and perceived community beliefs - the relative importance and value placed on the personal and community beliefs are defined by the community culture. Several studies have emphasized the importance of community attitudes, group norms or shared meanings in community behaviour (Hobfoll, 1998; Levine, 1998; St Lawrence, Eldridge, Reitman, Little, Shelby, \& Brasfield, 1998). In a socio-oriented African culture where collective values, communal outcomes and adherence to group norms are considered more important than individual values (Terblanche, 1996; Triandis, 1995; Van Dyk, 2001), the perception of the community stigma may play a more important role in behaviour patterns of the community than does the level of personal stigma held by individuals.

When interpreting the research results, it should be kept in mind that respondents were not recruited in a systematic way but that a sample of convenience was used. This resulted in an over-representation of the young, white and urban population. In a more representative sample the level of stigma might have proved to be different. Despite this shortcoming, the results of the current study may be used in the following ways:

- They may help people living with HIV to realize that their perception and fear of stigma in the community could well be overrated. The study shows that on a personal level many people are more understanding, especially when they are actually exposed to people with HIV.

- Community interventions may be developed to restrain the fear and moral judgements that are still prevalent. On a personal level exposure to HIV plays a major role in mitigating people's attitudes towards those with HIV. People with HIV should therefore be encouraged to disclose their status to family and friends since that would increase personal interaction, which may contribute to change in the level of judgement and personal stigma.

- The highly negative perceived community stigma that has evolved through various community processes over the past three decades, needs to be addressed. To change a community construction would require an open commitment from all sectors of the government, community leaders and the media to support and care for people with HIV. Information about HIV can help a lot to combat the fear people still have. More exposure and more talk in the community about how people with HIV can be supported may also contribute to a more realistic perception of community attitudes. This can be done through a process of action research that should involve opinion leaders, healthcare providers, families and caregivers. 
- The questionnaire that was developed for this exploratory study could be administered to a representative sample of the specific community to investigate whether the results that were obtained may in fact be generalized to the entire population.

\section{CONCLUSION}

HIV/AIDS stigma is a complicated issue with deep roots in the domains of gender, race, class, sexuality and culture. Although it is difficult to understand the process by which stigma is developed or changed on a community level, the clear need for establishing stigma-curbing interventions in the South African community cannot be denied. In addition to the counselling and education of HIV positive individuals to reduce their own fear of discrimination, interventions are needed on a community level, such as the implementation of Human Rights laws, the provision of social and healthcare services and social action campaigns to address the public's negative attitudes towards and perceptions of HIV/AIDS. This would contribute towards changing the context within which individuals and communities respond to HIV/AIDS (Parker et al., 2002).

Significant progress has been made in addressing discrimination in many countries around the world (Herek et al., 2002; Malcolm et al., 1998). However, as the number of people with HIV increases, the capacity of communities to care and support those with HIV needs to be strengthened. This is especially true for South Africa with its growing number of HIV/AIDS patients and the ever-escalating controversy about health services for them. We still need to know more about the impact of public policy on discriminatory responses and the relationship between knowledge of, and contact with, attitudes and behaviour on the one hand and the contextual factors that impact on the different forms of HIV/AIDS stigmatization on the other hand (Malcolm et al., 1998). There is a sense of urgency to act, as continued discrimination and stigmatization will only impede progress in the global effort to prevent, treat and control HIV/AIDS.

\section{ACKNOWLEDGEMENTS}

This paper reports on a pilot study conducted as part of the Serithi project done by the University of Pretoria under the auspices of the Medical Research Council (Unit for Maternal and Infant Health Care Strategies) in collaboration with Yale University funded by the National Institute of Health. We acknowledge the contributions of Prof. B. Jeffery, Dr M. Botes, Ms A de Villiers, Ms R. Kgabo, Ms F. Nkomo, Ms M Zondo, Ms R. Mkhondo, Ms J. Tatane (University of Pretoria) and Prof. B. Forsyth, Prof. K. Sikkema, Ms A. Stockman (Yale University).

\section{REFERENCES}

Abdool Karim, Q. (1998). Women and AIDS, the imperative for a gendered prognosis and preventive policy. Agenda, 39, 15-25.

Aggleton, P. (2000). HIV and AIDS-related stigmatization, discrimination and denial: Forms, contexts and determinants. Research studies form Uganda and India. UNAIDS Best practice collection. Geneva: UNAIDS. 
Ajzen, I. (1991). The theory of planned behavior. Organizational Behavior and Human Decision Processes, 50, 179-211.

Ajzen, I., \& Fishbein, M. (1980). Understanding attitudes and predicting social behavior. Englewood Cliffs, NJ: Prentice Hall.

Altenroxel, L. (2000). Two epidemics at once. Star, 5 July.

Alonzo, A. A., \& Reynolds, N. R. (1995). Stigma, HIVand AIDS: An exploration and elaboration of a stigma trajectory. Social Sciences and Medicine, 41(3), 303-315.

Ashforth, A. (2002). An epidemic of witcheraft? The implications of AIDS for the post-apartheid state. African Studies, 61(1), 121-142.

Baleta, A. (1999). Widespread horror over killing of AIDS activist in South Africa. Lancet, 353(9147), 130.

Baron, R. A., \& Byrne, D. (2002). Social psychology, understanding human interaction. Boston: Allyn \& Bacon.

Bond, V., Chase, E., \& Aggleton, P. (2002). Stigma, HIV/AIDS and prevention of mother-to-child transmission in Zambia. Evaluation and Program Planning, 25(4), 347-356.

Brown, L., Trujillo, L., \& Macintyre, K. (2001). Interventions to reduce HIV/AIDS stigma: What have we learned? Horizons Program, Tulane University, New Orleans.

Crawford, A. M. (1996). Stigma associated with AIDS: A meta-analysis. Journal of Applied Social Psychology, 26(5), 398-416.

De Bruyn, M. (1992). Women and AIDS in developing countries. Social Science and Medicine, 34, 249-262.

De Bruyn, T. (1999). HIV/AIDS and discrimination 2: Stigma and discrimination: Definitions and concepts. Ottawa: Canadian HIV/AIDS Legal Network and the Canadian AIDS Society.

Department of Health. (2000a). Living openly, HIV positive South Africans tell their stories. Report commissioned by the Beyond Awareness Campaign, HIV/AIDS and STD directorate, Department of Health, Pretoria.

Department of Health. (2000b). HIV/AIDS/STD strategic plan for South Africa 2000-2005. Pretoria: Department of Health.

Department of Health. (2003). Summary report: National HIV Sero-prevalence survey of women attending public antenatal clinics in South Africa, 2002. Pretoria: Department of Health, Directorate Health Systems Research and Epidemiology.

Department of National Health and Population Development. (1993). AIDS research: Feedback session. Pretoria: AIDS Unit.

Eagle, A. H., \& Chaiken, S. (Eds). (1993). The psychology of attitudes. Fort Worth (TX): Harcourt Brace Jovanovich.

Evian, C. (1992). AIDS and the cycle of poverty. AIDS Scan, 4(4), 3.

Forman, L. (2003). The constitutional imperative to treat: The South African government's constitutional obligations to provide antiretroviral medicines. Paper at the South African AIDS Conference, Durban, 3-6 August.

Gebrekristos, H., Abdool Karim, Q., \& Lurie, M. (2003). Disclosure of HIV status for patients on HAART: Implications for treatment adherence and sexual behaviour. Paper at the South African AIDS Conference, Durban, 3-6 August.

Gergen, K. J. (1994). Realities and relationships: Soundings in social construction. Cambridge (Mass): Harvard University Press.

Goffman, E. (1963). Stigma: Notes on the management of spoiled identity. Englewood Cliffs, NJ: Prentice Hall.

Gostin, L.O., \& Weber, D. W. (1998). The AIDS Litigation Project: HIV/AIDS in the courts in the 1990s, Part 2. AIDS and Public Policy Journal, 13, 3-13.

Green, G. (1995). Attitudes towards people with HIV: Are they as stigmatizing as people with HIV perceive them to be. Social Science and Medicine, 41(4), 557-568.

Grimond, J. (2001). A survey of South Africa. Africa's great black hope. The Economist, 24 February 24-2 March, 3-16.

Hassan, F. (2003). 'Treat the people ... now' Human rights and the law in the struggle for treatment. Paper at the South African AIDS Conference, Durban, 3-6 August.

Herek, G. M. (1999). AIDS and stigma. American Behavioral Scientist, 42(7), 1102-1112.

Herek, G. M., \& Glunt, E. K. (1991). AIDS-related attitudes in the United States: A preliminary conceptualization. The Journal of Sex Research, 28, 99-123. 
Herek, G. M., \& Capitanio, J. P. (1993). Public reactions to AIDS in the United States: A second decade of stigma. American Journal of Public Health, 83(4), 574-577.

Herek, G. M., \& Capitanio, J. P. (1997). AIDS stigma and contact with persons with AIDS: Effects of direct and vicarious contact. Journal of Applied Social Psychology, 27(1), 1-36.

Herek, G. M., Capitanio, J. P., \& Widaman, K. F. (2002). HIV-related stigma and knowledge in the United States: Prevalence and Trends, 1991-1999. American Journal of Public Health, 92(3), 371-377.

Hobfoll, S. E. (1998). Ecology, community and AIDS prevention. American Journal of Community Psychology, 26(1), 133-144.

Keeten, C. (1999). HIV stigma hinders disclosure. The Sowetan, 12 January, p. 11.

Kerlinger, F. N., \& Lee, H. B. (2000). Foundations of behavioral research (4th ed.). Fort Worth: Harcourt College Publishers.

Krautkamer, R. (2000). Can doctors refuse to treat HIV patients. Cape Times, 3 May.

Levine, M. (1998). Prevention and community. American Journal of Community Psychology, 26(2), 189-206.

Lie, G., \& Biswalo, P. (1994). Perceptions of the appropriate HIV/AIDS counselor in Arusha and Kilimanjaro regions of Tanzania: Implications for hospital counselling. AIDS Care, 6(2), 139151.

Lindegger, G., \& Wood, G. (1995). The AIDS crisis: Review of psychological issues and implementations, with special reference to the South African situation. South African Journal of Psychology, 25(1), 1-11.

Link, B., \& Phelan, J. (2002). On stigma and its public health implications. In http://www:stigmaconference:nih:gov=LinkPaper:htm

Maman, S., Mbwambo, J., Hogan, M., Kilonza, G., Sweat, M., \& Weiss, E. (2001). HIVand partner violence: Implications for HIV voluntary counselling and testing programmes in Dar es Salaam, Tanzania. New York: Population Council.

Malcolm, A., Aggleton, P., Bronfman, M., Galvao, J., Mane, P., \& Verrall, J. (1998). HIV-related stigmatization and discrimination: Its forms and contexts. Critical Public Health, 8(4), 347-370.

McNeil, D. G. Jr. (1998). Neighbors kill an HIV-positive AIDS activist in South Africa. New York Times, 28 Decembe, p. A5.

Miles, M. B., \& Huberman, A. M. (1994). Qualitative data analysis, an expanded sourcebook (2nd ed.). Thousand Oaks: Sage.

Mwondela, K., \& Sakufiwa, M. (2003). Law and policy addressing stigma and discrimination. Paper at the South African AIDS Conference, Durban, 3-6 August.

National Association of People with AIDS. (1992). HIV in America: A profile of the challenges facing Americans living with HIV. Washington, DC: Author.

Ngqlyaza, B. (2000a). Lawyers criticize SAA hiring. Business Day, 9 May.

Ngqlyaza, B. (2000b). Soldiers fear virus more than bullets. Business Day, 8 May.

Parker, R., Aggleton, P., Attawell, K., Pulerwits, J., \& Brown, L. (2002). HIV/AIDS-related stigma and discrimination: A conceptual framework and an agenda for action. Horizons Program. New York: The Population Council.

Richter, M. (2003). Gender, HIV/AIDS and customary law. Paper at the South African AIDS Conference, Durban, 3-6 August.

Sakufiwa, M. (2003). The role of the state in promoting and protecting the rights of people living with and affected by HIV/AIDS. Paper at the South African AIDS Conference, Durban, 3-6 August.

Schoub, B. (1992). AIDS in South Africa-into the second decade. South African Medical Journal, $81,55-56$.

Sherriffs, P. (1997). A time for review-HIV in a democratic South Africa. Positive Outlook, 4(3), $10-12$.

Shisana, O., \& Simbayi, L. (2002). South African national HIV prevalence, behavioural risks and mass media household survey 2002. Nelson Mandela/HSRC study of HIV/AIDS. Cape Town: Human Sciences Research Council.

Skinner, D. (2002). Stigma and the ABCD: A consideration in South Africa. Paper read at the African Conference on the Social Aspects of HIV/AIDS Research: Promoting an African Alliance to mitigate the impact of the epidemic in Southern Africa. Pretoria: Human Sciences Research Council, 1-4 September. 
St Lawrence, J., Husfeldt, B., Kelly, J., Hood, H., \& Smith, S. (1990). The stigma of AIDS: Fear of disease and prejudice towards gay men. Journal of Homosexuality, 19, 85-101.

St Lawrence, J. S., Eldridge, G. D., Reitman, D., Little, C. E., Shelby, M. C., \& Brasfield, T. L. (1998). Factors influencing condom use among African American women: Implications for riskreduction interventions. American Journal of Community Psychology, 26(1), 7-28.

Strebel, A. (1993). Women and AIDS: A study of issues in the prevention of HIV infection. Unpublished PhD thesis. Cape Town: University of Cape Town.

Streek, B. (2001). HIV positive kids must go to school. Cape Argus, 2 November.

Terblanche, F. H. (1996). Die individualisme-kollektiwisme-dimensie van kulturele variasie: Implikasies vir mondelinge onderrigkommunikasie. (The individualism-collectivism dimension of cultural variation: Implications for teaching communication). Communicare, 15(2), 57-90.

Triandis, H. C. (1995). Individualism and collectivism. Westview Press.

UNAIDS. (2000). Protocol for the identification of discrimination against people living with HIV. Best practices collection. Geneva: UNAIDS.

Van Dyk, A. C. (2001). HIV/AIDS care and counselling: A multidisciplinary approach (2nd ed.). Cape Town: Pearson Education South Africa.

Viol, J. (2000). Prejudiced employers paying off HIV positive workers. Cape Argus, 17 July.

Warwick, I., Bharat, S., Castro, R., Garcia, R., Leshabari, M., Singhanetra-Renard, A., \& Aggleton, P. (1998). Household and community responses to AIDS in developing countries. Critical Public Health, 8(4), 291-310.

Westbrook, L. E., \& Bauman, L. J. (1996). Perceived stigma of HIV/AIDS scale. Bronx, New York: Albert Einstein College of Medicine.

Yoshika, M., \& Schustack, A. (2001). Disclosure and HIV status: Cultural issues of Asian patients. AIDS patients care and STD's, 15(2), 77-82. 